\title{
Addison's disease and diffuse cerebral sclerosis ${ }^{1}$
}

\author{
D. HOEFNAGEL, A. BRUN, S. H. INGBAR, AND H. GOLDMAN
}

From the Departments of Medicine and Pathology, Dartmouth Medical School, Hanover, New Hampshire, the C.S. Kubik Laboratory for Neuropathology, Massachusetts General Hospital, and the Thorndike Memorial Laboratory, Boston City Hospital, Boston, Massachusetts, U.S.A.

In an earlier paper (Hoefnagel, van den Noort, and Ingbar, 1962), the association of diffuse cerebral sclerosis and adrenal cortical atrophy in a young boy was described and reports in the literature of five similar cases were reviewed. Three more instances of this syndrome have been recorded since 1962 (Fanconi, Prader, Isler, Lüthy, and Siebenmann, 1963; Blaw, Osterberg, Kosak, and Nelson, 1964; Dubois, Loeb, Périer, Parmentier, and Szliwowski, 1964) and the present report describes the clinical and pathological features of this entity in yet another young male.

\section{CASE HISTORY}

A Caucasian male was admitted to the hospital at the age of $10 \frac{1}{2}$ years because of diffuse hyperpigmentation of the skin for three years and progressive neurological disease of about six months' duration. He had been born after a normal, full-term pregnancy and a normal delivery with a birth weight of $3 \mathrm{~kg}$. (6 lb. $10 \mathrm{oz}$.). The neonatal period was uneventful, and physical growth, mental, and social development progressed normally. He had had uncomplicated measles, chickenpox, and mumps; there were no untoward reactions to a full complement of immunizations. The patient was the older of two children; a sister, seven years younger, was healthy. The father and mother were 21 and 20 years old respectively at the time of the patient's birth; the mother denied having had miscarriages. The parents were not consanguineous and there was no knowledge of neurological disease, Addison's disease, or pigmentary disorders in the family. Between the ages of 1 and 8 years the patient had mild chronic allergic rhinitis and an occasional attack of asthmatic bronchitis. At the age of $7 \frac{1}{2}$ years he underwent a tonsillectomy; the procedure was uneventful, but about 12 hours postoperatively there occurred intractable vomiting culminating in coma, shock, and hyperthermia. The child recovered rapidly after treatment with intravenous fluids and cortisone. The patient had always had a 'sensitive' skin; small wounds would take a long time to heal and they often became infected. The skin tanned easily in the summer with normal fading of the pigmentation in the winter. At the age of 7 years, scars of the skin were noted

'Supported by grants (GM 10210, AM 00267 and 2B5393) from the United States Public Health Service and a grant from the Charles $\mathbf{H}$. Hood Dairy Foundation. to be unusually dark and at about that time there began a slowly progressive, diffuse hyperpigmentation of the skin, which did not fade during the winter. In all other respects the patient was in apparent good health until the age of 10 years when he developed a paralysis of the left lateral rectus muscle and upon examination was also found to have poor vision, bilateral nerve deafness, dysarthria, and unsteadiness of gait. The cerebrospinal fluid pressure was 120; it showed no cells, the Pandy reaction was positive, sugar $90 \mathrm{mg}$. and total protein 147 mg. per $100 \mathrm{ml}$. A pneumoencephalogram was normal. The child's general health remained excellent, but the neurological disorder worsened steadily with increasing

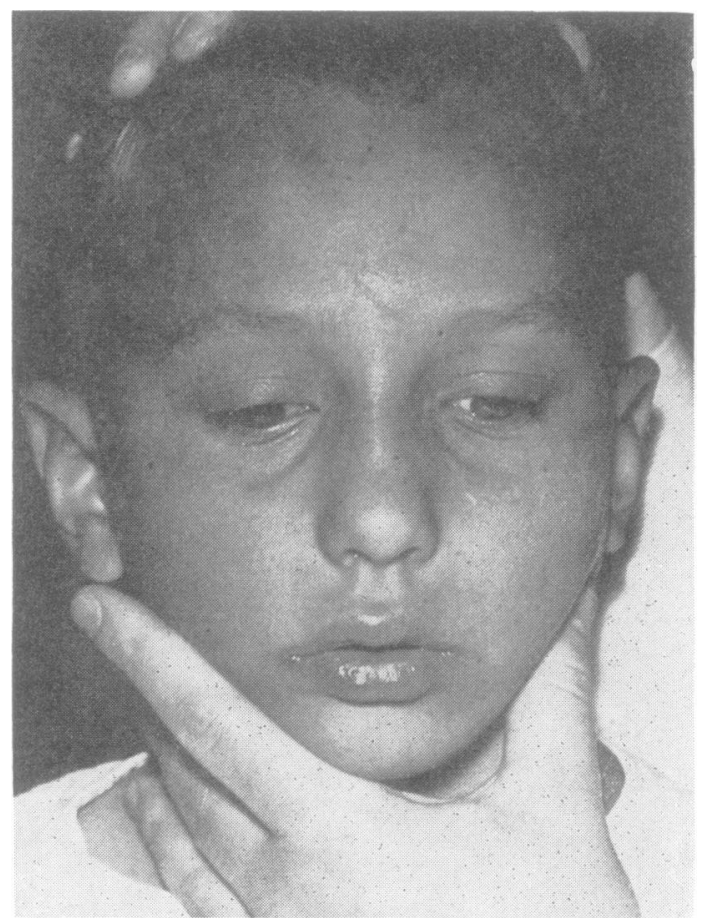

FIG. 1. The patient at $10 \frac{1}{2}$ years of age, showing diffuse hyperpigmentation of the skin with accentuation in small scars of the forehead. 
deafness, blindness, dysarthria, and ataxia; in the weeks before admission he became doubly incontinent. There were no headaches, vomiting or convulsions.

Upon admission to the hospital the following were the pertinent findings: height $145 \mathrm{~cm}$. (57 in.), weight $42 \mathrm{~kg}$. (93 lb.), blood pressure $115 / 85 \mathrm{~mm}$. $\mathrm{Hg}$, pulse $88 / \mathrm{min}$., and respiration $18 / \mathrm{min}$. There was marked diffuse hyperpigmentation of the skin (Fig. 1) accentuated in scars; the mucous membranes of the mouth were free of pigmentation. Heart, lungs, abdomen, and genitalia were normal. The sense of smell was intact. The patient walked into objects around him and there was no reaction to threatening visual stimuli. The optic disks were flat, sharply outlined and pale; the retinae and maculae were otherwise normal. There were conjugate, roving movements of the eyes over a full range without a quick component. The pupils were equal in size and reacted sluggishly to light directly and consensually; the corneal reflexes were normal. There was no weakness of the facial muscles. There was profound bilateral deafness. The patient walked with a stooped posture, slow, shuffling steps, and marked ataxia. Involuntary movements were absent and resistance to passive manipulation of the limbs was normal. The deep tendon reflexes were active and symmetrical, the plantar responses were extensor, the abdominal reflexes absent and the cremasterics normal. The heel cords were tight and there was bilateral ankle clonus. Sensation to pinprick was intact.

Laboratory examinations showed the following: urine analysis was normal, haemoglobin 14.8 g. per 100 ml.; normal total and differential white cell counts; serological test for syphilis and skin test for tuberculosis were negative; blood urea nitrogen $9 \mathrm{mg}$. per $100 \mathrm{ml}$., fasting blood sugars varied between 74 and $112 \mathrm{mg}$. per $100 \mathrm{ml}$. The serum chloride levels varied between 96 and 105 , sodium between 133 and 146, potassium between 4.6 and 5.4, and $\mathrm{CO}_{2}$-combining power between 22 and $23.2 \mathrm{mEq}$. per $1,000 \mathrm{ml}$. There were no calcifications on a radiograph of the abdomen and radiographs of the skull and chest were normal. Electrocardiography and electroencephalography showed normal patterns. Examination of the urine with cresyl violet and toluidine blue was negative for metachromatic mucolipids in the sediment and metachromatic soluble lipids.

Urinary excretion of 17-hydroxycorticoids, during four days of control collections, ranged between 0.2 and $0.4 \mathrm{mg}$. per 24 hours. In the same specimens, the level of 17-ketosteroids was too low for accurate measurement, even though twice the usual volume of urine was extracted; the results indicated that the excretion of 17ketosteroids could not have exceeded $0.4 \mathrm{mg}$. per 24 hours. Following the control collections, the patient received, over five consecutive days, a total of 240 units of A.C.T.H., either intravenously or as A.C.T.H. gel intramuscularly. Despite these large doses of A.C.T.H., no increase in the urinary excretion of 17-hydroxycorticoids or 17-ketosteroids was observed in 24-hour urine collections during the five days.

A diagnosis of Addison's disease associated with diffuse cerebral sclerosis was made. After discharge from the hospital the neurological disorder worsened progressively, not influenced by steroid therapy; the patient developed a tetraplegia in flexion and died at the age of 11 years and 3 months.

FINDINGS AT GENERAL NECROPSY On gross examination, congestion and oedema of the lungs with foci of atelectasis were noted. The pituitary, thyroid, pancreas, and testes were normal, but careful dissection was necessary to locate the markedly atrophied adrenal glands, each of which weighed about $1 \mathrm{~g}$. (normal for age 3.5-4 g.). On cross section the corticomedullary junctions of the adrenals were distinct, but the cortex was less than $1 \mathrm{~mm}$. thick. Pertinent microscopic findings were as follows: the lungs showed acute and chronic bronchopneumonia; in the skin there was heavy melanin deposition in the basal layer of the epidermis with a small number of melaninladen chromatophores in the upper dermis. The testicular tissue showed thickened basement membranes with absence of Leydig cells, spermatogenesis, and mitotic activity. The pituitary gland was normal. The periadrenal fat was atrophic. About two-thirds of the adrenal glands consisted of normal medulla; no defined zona glomerulosa could be seen. There were several small adrenocortical nodules formed by large eosinophilic cells with small eccentric nuclei and fine granular cytoplasm (Fig. 2).

DESCRIPTION OF THE BRAIN (CASE X-379, MGH) The brain weighed 1,100 g. and had a normal shape and surface

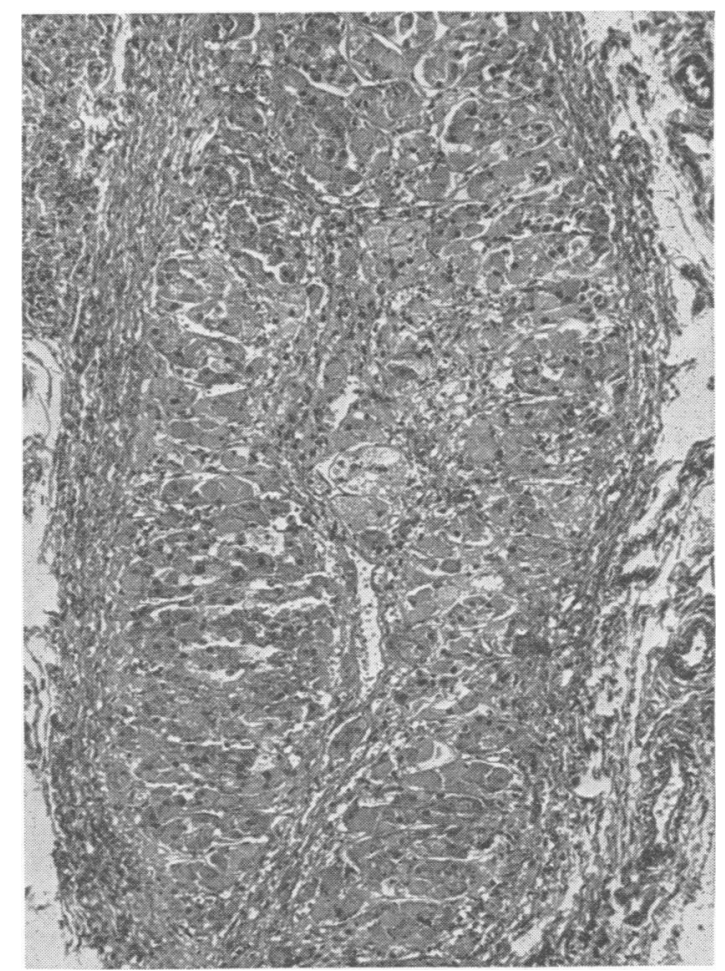

FIG. 2. Cross section of adrenal, showing the atrophy of the cortex (haematoxylin and eosin, $\times 50$ ). 

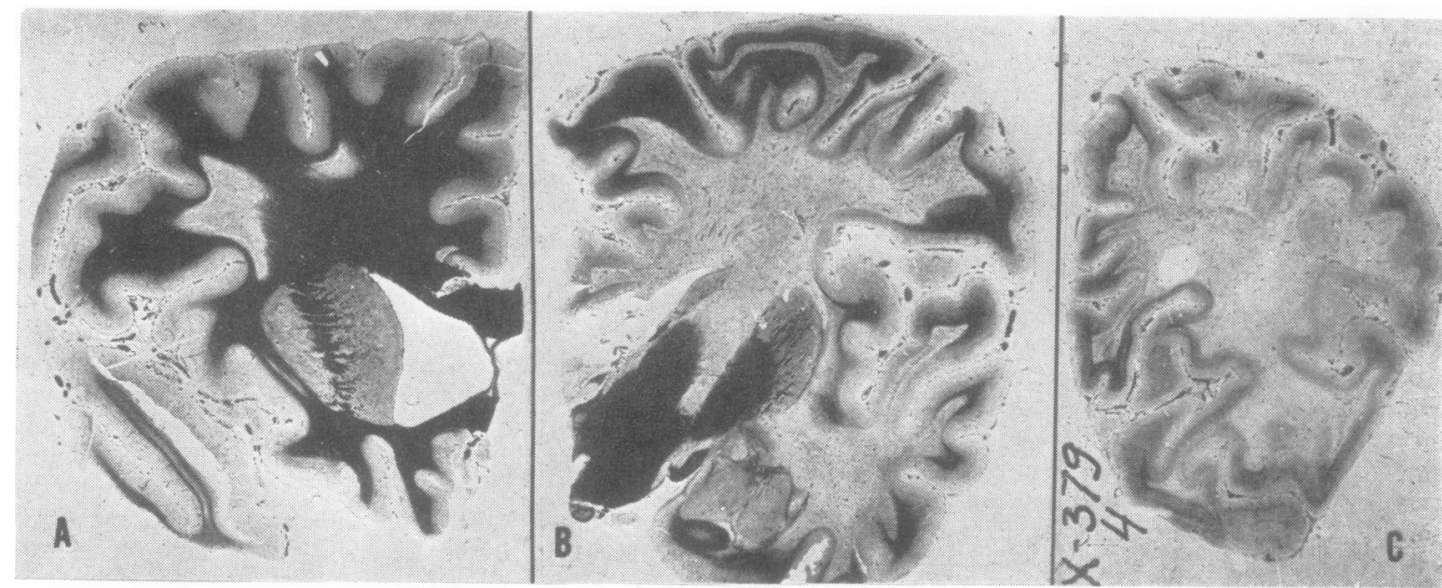

FIG. 3. Coronal sections through the frontal $(A)$, parietal $(B)$, and occipital $(C)$ areas of the brain, showing the varying degrees of demyelination (myelin stain).

configuration. The optic nerves were slightly atrophic and of firm consistency. Coronal sections of the brain showed widespread destruction of white matter bilaterally in the occipital, temporal, and parietal lobes with less extensive changes in the frontal lobes (Fig. 3); these areas looked grey and had a rubbery consistency. In the frontal lobes there were several sharply delineated subcortical lesions of varying size. The thalamus, hypothalamus, pallidum, pituitary stalk, and mamillary bodies were normal. The ventricular system was slightly widened in its occipital portions. The cortex of the cerebral hemispheres was normal except where the white matter lesions had extended to the pial membrane at the inferiortemporal and insular cortex bilaterally. The cerebellum was normal. The mesencephalic peduncles were atrophic and gelatinous, particularly in their lateral halves. All through the brain-stem the pyramidal tracts were grey and shrunken and the medulla and upper cervical cord were reduced in width.

The brain was extensively sampled, including the use of whole hemisphere sections, and examined with the following stains: haematoxylin and eosin, cresyl violet, Spielmeyer (for myelin), acid cresyl violet (for metachromatic substances), Sudan red (for fatty breakdown products), and silver stains (for axones and neurofibrils).

MICROSCOPIC INVESTIGATION The affected areas of white matter showed extensive demyelination with complete loss of the basic structural pattern. In some areas there was scar tissue formed by protoplasmic and fibrillary astrocytes and a glial fibrillary meshwork containing macrophages, which were often clustered perivascularly in wide collars together with lymphocytes and plasma cells. The macrophages contained red sudanophilic material, which did not react metachromatically. Axons were present in reduced numbers. There also were degenerative cell changes including pyknotic oligodendroglial nuclei surrounded by swollen eosinophilic cytoplasm and larger cells showing karyorrhexis. In areas with damaged U-fibres there were cortical changes, par- ticularly in the deep layers, with loss of cortical myelin and degeneration of nerve cells which were encrusted with a granular pigment. The hypothalamus showed $\omega_{0}$ more discrete lesions than the brain paranchyma else where; the paraventricular nuclei were normal. The optic of tracts showed symmetrical demyelination confined to the superior halves; demyelination was also noted in the optic chiasm. The central portions of the optic nerves were partly demyelinated; this change reached the $\mathbb{D}$ superior surface only. The cellular response here was mile with scattered astrocytes, but few lymphocytes and goog g preservation of the basic tissue pattern, whereas in the optic tracts there was a marked lymphocytic and gli $\overrightarrow{0}$ response and more complete loss of myelin with extensive of scarring. The cerebellum showed only minimal changes. The mesen- and rhombencephalon showed demyelinated lesions similar to those of the cerebral white matter, though much less extensive. The pyramidal tracts showed advanced demyelination as far down as the cervical cord.

\section{DISCUSSION}

Adrenocortical hypofunction in the present patient evidently began at about $7 \frac{1}{2}$ years of age, when increasing cutaneous pigmentation became apparent and when the child had an episode typical of postoperative adrenal crisis relieved by fluid replacement and cortisone. Nevertheless, despite the discontinuation of cortisone therapy, the patient was quite well until the age of 10 when the neurological disorder became manifest. At the time of admission to the hospital, evidence of adrenocortical failure, other 9 than hyperpigmentation, was lacking. Presumably, an adequate level of basal corticosteroid secretion was maintained; secretion was not increased, how- $\vec{N}$ ever, in response to large doses of A.C.T.H. These or findings indicate a complete lack of adrenocortical $N$ reserve. The intense cutaneous pigmentation in- N్ 
dicated hypersecretion of A.C.T.H. In this respect the present patient differs from one previously reported (Hoefnagel et al., 1962), who showed adrenocortical atrophy at necropsy, while during life there had not been cutaneous hyperpigmentation; evidence of A.C.T.H. production in the anterior pituitary gland was lacking (absence of basophilic cells), although the patient had not received replacement therapy with steroids. In the present patient the clinical course of the neurological disorder and the subsequent neuropathological findings were those of demyelinating diffuse cerebral sclerosis of the sudanophilic type.

Some pertinent features of cases conforming to this syndrome reported to date have been set out in a Table; only those with complete pathological descriptions have been included. In a similar tabulation, Dubois et al. (1964) excluded the case described by Hoefnagel et al. (1962), because the authors considered it to be a case of tuberous sclerosis associated with adrenocortical atrophy; however, after personal examination of the histological material the authors confirmed the diagnosis of sudanophilic diffuse cerebral sclerosis (Dr. O. Périer, personal communication). In addition to the cases listed in the Table, several more are known to us to have been observed in other centres; all of these patients have been young males. In at least one instance, a boy

\section{TABLE}

SUMMARY OF CASES REPORTED IN THE LITERATURE

\begin{tabular}{|c|c|c|c|}
\hline Reference & $\begin{array}{l}\text { Age of } \\
\text { Onset of } \\
\text { Addison's Disease } \\
(y r .)\end{array}$ & $\begin{array}{l}\text { Age of } \\
\text { Onset of } \\
\text { Cerebral } \\
\text { Sclerosis } \\
(y r .)\end{array}$ & $\begin{array}{l}\text { Age at } \\
\text { Death }(y r .)\end{array}$ \\
\hline
\end{tabular}

Siemerling and

Creutzfeldt (1923)

Pfister (1936)

Gagnon and Leblanc,

case 3 (1959)

Lichtenstein and

Rosenbluth, case 3

(1959)

Brun and Voigt

(1960)

Hoefnagel et al.

(1962)

Fanconi et al. (1963)

Blaw et al. (1964)

Dubois et al. (1964)

Present case

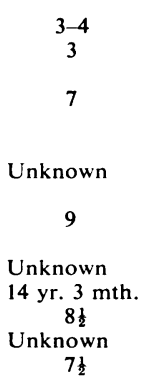

$\begin{array}{cc}6 \frac{1}{2} & 7 \\ 7 & 8 \frac{1}{2} \\ 9 & 10 \\ & \\ 5 & 7 \\ 9 & 10 \frac{1}{2} \\ 5 \text { yr. } 5 \text { mth. } & 17 \frac{1}{2} \\ 8 \frac{1}{2} & 9 \text { yr. } 9 \text { mth. } \\ 7-8 & 10 \\ 10 & 11 \text { yr. } 3 \text { mth. }\end{array}$

previously recorded in the literature as a case of Addison's disease (Meakin, Nelson, and Thorn, 1959), has since died of diffuse cerebral sclerosis (Mosier, quoted by Fanconi et al., 1963). An Xchromosomal recessive mode of inheritance has to be considered with transmission of the trait to half of the male offspring through unaffected carrier mothers. Further support for this mode of inherit- ance comes from earlier reports of affected male siblings (Hoefnagel et al., 1962; Gagnon and Leblanc, 1959) and of maternal male relatives. A maternal uncle of the patient of Blaw et al. (1964) had died at the age of 14 years of diffuse cerebral sclerosis, sudanophilic type; no information was available on hyperpigmentation of the skin or the histopathology of the adrenal glands. A maternal cousin of the case reported by Dubois et al. (1964) had died of a neurological disorder, clinically diagnosed as diffuse cerebral sclerosis. Future work in this syndrome should include studies to test the assumption that the gene for the trait is located on the $\mathrm{X}$ chromosome; tests for colour vision, typing for the $\mathrm{Xg}$ blood group, and endocrinological studies in the female carriers are to be considered. While assuming that the cause of the syndrome is genetic in nature, any attempt to explain the pathogenetic relationship of the neurological and endocrinological aspects has to be even more speculative. In the cases hitherto reported, evidence of adrenocortical failure preceded or coincided with the onset of manifestations of the disease of the nervous system (see Table). In those patients in whom the diagnosis of adrenocortical hypofunction was made during life with adequate response to treatment of the endocrinological features (Brun and Voigt, 1960; Fanconi et al., 1963; Dubois et al., 1964) the nervous system disease nevertheless pursued its course relentlessly. It is possible that the adrenocortical failure occurs secondary to primary lesions of the nervous system; another possibility to be considered is that a genetic defect acts through a metabolic pathway pertinent to the integrity of development of the adrenal cortex and maintenance of myelination of the nervous system.

\section{SUMMARY}

Clinical, laboratory, and pathological observations are described in a young boy affected by a syndrome consisting of Addison's disease and diffuse cerebral sclerosis of the sudanophilic type. The findings are compared with those of similar cases, previously reported. It is likely that the syndrome is caused by an X-chromosomal genetic defect.

We wish to thank the following colleagues for help in this study: Dr. Jack E. Hale, St. John's Hospital, Tulsa, Oklahoma; Dr. John F. Crigler Jr., Children's Hospital Medical Center, Boston, Massachusetts; Dr. N. S. Halmi, State University of Iowa, Iowa City, Iowa, and Dr. K. Benirschke, Dartmouth Medical School, Hanover, New Hampshire.

\section{REFERENCES}

Blaw, M. E., Osterberg, K., Kosak, P., and Nelson, E. (1964). Sudanophilic leukodystrophy and adrenal cortical atrophy. Arch. Neurol. (Chic.), 11, 626-631. 
Brun, A., and Voigt, G. E. (1960). Entzündliche cerebrale Sklerose mit Nebenniereninsuffizienz. Dtsch. Z. Nervenheilk., 180, 654-664.

Dubois, R., Loeb, H., Périer, O., Parmentier, R., and Szliwowski, H. (1964). Maladie d'Addison et sclérose diffuse de Schilder. Helv. paediat. Acta, 19, 528-555.

Fanconi, A., Prader, A., Isler, W., Lüthy, F., and Siebenmann, R. (1963). Morbus Addison mit Hirnsklerose im Kindesalter. Ein hereditäres Syndrom mit X-chromosomaler Vererbung? Ibid., 18, 480-501.

Gagnon, J., and Leblanc, R. (1959). Sclérose cérébrale diffuse avec mélanodermie et atrophie surrénale. Un. méd. Can., 88, 392-415.
Hoefnagel, D., van den Noort, S., and Ingbar, S. H. (1962). Diffuse Z cerebral sclerosis with endocrine abnormalities in young males. (D Brain, 85, 553-568.

Lichtenstein, B. W., and Rosenbluth, P. F. (1959). Schilder's disease with melanoderma. J. Neuropath. exp. Neurol., 18, 384-396.

Meakin, J. W., Nelson, D. H., and Thorn, G. W. (1959). Addison's disease in two brothers. J. clin. Endocr., 19, 726-731.

Pfister, R. (1936). Beitrag zur Kenntnis der diffusen Hirnsklerose. Arch. Psychiat. Nervenkr., 105, 1-16.

Siemerling, E., and Creutzfeldt, H. G. (1923). Bronzekrankheit und sklerosierende Encephalomyelitis (Diffuse Sklerose). Ibid., 68, 217-244. 